\title{
PERDAS DE NUTRIENTES POR EROSÃO E SUA DISTRIBUIÇÃO ESPACIAL EM ÁREA SOB CANA-DE-AÇÚCAR ${ }^{1}$
}

\section{RICARDO IZIDORIO ${ }^{2}$, MARCÍLIO V. MARTINS FILHO ${ }^{3}$, JOSÉ MARQUES JÚNIOR ${ }^{3}$, ZIGOMAR M. DE SOUZA ${ }^{4}$, GENER T. PEREIRA ${ }^{5}$}

RESUMO: O presente trabalho teve como objetivo principal determinar as perdas de nutrientes por erosão em entressulcos, sulcos e global (entressulcos + sulcos, A), em área cultivada com cana-deaçúcar submetida à queima da palhada na sua pré-colheita, na Fazenda Santa Bárbara, localizada em Guariba - SP, sob um Latossolo Vermelho eutroférrico (LVef). Parcelas experimentais foram submetidas à chuva simulada com intensidade de $80 \mathrm{~mm} \mathrm{~h}^{-1}$, durante 65 minutos. Análises do sedimento erodido indicaram altas taxas de enriquecimento: 1,62 (matéria orgânica, $\mathrm{MO}$ ); 4,30 (P); $1,17(\mathrm{~K}) ; 1,33(\mathrm{Ca})$ e 1,24 (Mg) vezes em relação ao solo original. As perdas de solo e nutrientes, em função do tipo de erosão, obedeceram à seguinte ordem: sulcos $>$ global $>$ entressulcos. Análises geoestatísticas indicaram que as perdas de solo (A), MO, P, K e Ca por erosão apresentaram forte grau de dependência espacial, enquanto as perdas de Mg tiveram moderado grau de dependência espacial. Mapas da distribuição dos padrões de variabilidade espacial das perdas por erosão indicaram que o cultivo de cana-de-açúcar conserva as propriedades químicas e físicas do solo na maior parte da área.

PALAVRAS-CHAVE: erosão em entressulcos, erosão em sulcos, geoestatística.

\section{NUTRIENT LOSSES BY EROSION AND SPATIAL DISTRIBUTION IN AREA CULTIVATED WITH SUGARCANE}

\begin{abstract}
The principal objective of this study was to determine the nutrient losses from interrill, rill and global erosion (interrill + rill, A) in an area cultivated with sugarcane at Santa Bárbara farm, in the region of Guariba (SP), in a Typic Haplustox, very clayey texture. The cane was burnt prior to harvest. The plots were submitted to a rainfall simulation at intensity of approximately $80 \mathrm{~mm} \mathrm{~h}^{-1}$ for about 65 minutes. Analyses of the sediment indicated much higher enrichment ratio: 1.62 (organic matter, $\mathrm{OM}) ; 4.30(\mathrm{P}) ; 1.17(\mathrm{~K}) ; 1.33(\mathrm{Ca})$ and $1.24(\mathrm{Mg})$ times when compared with the original soil. The nutrients and the soil losses in function of the erosion type have the following order: rill > interrill $>$ large plots. Geostatistical analyses indicated that the soil erosion (A) and OM, P, K e Ca losses have a strong spatial dependence degree, while Mg losses have a moderate spatial dependence degree. Distribution maps showing spatial patterns variability of the erosion losses indicated that sugarcane culture conserves the soil chemical and physical properties in the greatest part of the area.
\end{abstract}

KEYWORDS: interrill erosion, rill erosion, geostatistics.

\footnotetext{
${ }^{1}$ Extraído da Dissertação de Mestrado do primeiro autor.

${ }^{2}$ Eng ${ }^{-}$Agr ${ }^{0}$, Mestre em Agronomia, Departamento de Solos e Adubos, UNESP, Jaboticabal - SP, mfilho@ fcav.unesp.br .

${ }^{3}$ Prof. Doutor, Departamento de Solos e Adubos, UNESP, Jaboticabal - SP.

${ }^{4} \mathrm{Eng}^{\mathrm{o}} \mathrm{Agr}^{\mathrm{O}}$, Doutor em Agronomia, DEG/UFLA, Lavras - MG.

${ }^{5}$ Prof. Doutor, Departamento de Ciências Exatas, UNESP, Jaboticabal - SP.

Recebido pelo Conselho Editorial em: 5-11-2003

Aprovado pelo Conselho Editorial em: 13-9-2005
} 


\section{INTRODUÇÃO}

As perdas de nutrientes podem ocorrer associadas ao transporte pelo fluxo ou adsorvidas ao sedimento carreado pela enxurrada (WALTON et al., 2000). É conhecido que sistemas de conservação do solo, como o plantio direto e o cultivo mínimo, podem reduzir as perdas por erosão, em comparação ao sistema convencional (WALTON et al., 2000). Então, as perdas de solo e nutrientes por erosão, em sistemas que eliminam os resíduos culturais, como é o caso no cultivo da cultura de cana-de-açúcar, com a queima da palhada antes da colheita, devem ser avaliadas.

A erosão hídrica do solo tem sido avaliada considerando-se dois processos distintos: erosão em entressulcos e em sulcos (FOSTER, 1982; MARTINS FILHO, 1999). A erosão em entressulcos é um processo caracterizado pelo desalojamento das partículas de um solo, como conseqüência do impacto das gotas da chuva e o subseqüente transporte das partículas por um fino fluxo superficial de enxurrada (FOSTER, 1982). Já a erosão em sulcos ocorre em locais onde um fluxo concentrado de água flui em canais efêmeros, os quais podem ter por origem processos erosivos anteriores, as feições da topografia, a rugosidade do solo e as marcas ou traços de equipamentos de cultivo (MARTINS FILHO, 1999). Assim, a erosão nas áreas entre os sulcos é designada entressulcos. São bastante usuais, na área de conservação do solo, avaliações da erosão global, que é resultante da ação conjunta dos processos erosivos em entressulcos e em sulcos.

Segundo NEARING et al. (2001), a separação do processo de erosão em entressulcos e em sulcos pode ajudar a identificar fontes potenciais de sedimentos. Isso, segundo os mesmos, é extremamente importante em termos de modelagem da distribuição de produtos químicos nas áreas agrícolas, especialmente daqueles que são fortemente adsorvidos pelas partículas do solo. O sedimento das áreas entressulcos pode carrear altas concentrações de contaminantes, quando produtos químicos são aplicados em superfície. Em contraste, o sedimento dos sulcos pode conter mais contaminantes quando os produtos químicos são aplicados de forma localizada e concentrados.

Há na literatura metodologias específicas para a avaliação dos processos erosivos em entressulcos, em sulcos e global (LAL \& ELLIOT, 1994). Contudo, trabalhos considerando as perdas de nutrientes com o processo de erosão de forma global ou separando-o em entressulcos e em sulcos têm relevante importância, visto contribuírem para a identificação das possíveis fontes não-pontuais de poluição.

Em função do exposto, o presente trabalho teve os objetivos de determinar as perdas de nutrientes por erosão em entressulcos, sulcos e global em área cultivada com cana-de-açúcar submetida à queima da palhada e avaliar a distribuição espacial das referidas perdas em função do processo de erosão global.

\section{MATERIAL E MÉTODOS}

O trabalho foi conduzido em área da Fazenda Santa Bárbara - Usina São Martinho S.A., cultivada há mais de 30 anos com cana-de-açúcar, no município de Guariba - SP, nas coordenadas geográficas de $21^{\circ} 19^{\prime}$ a $21^{\circ} 20^{\prime} \mathrm{S}$ e $48^{\circ} 13^{\prime}$ a $48^{\circ} 14^{\prime} \mathrm{W}$. O solo local foi classificado como Latossolo Vermelho eutroférrico (LVef), textura muito argilosa (EMBRAPA, 1999), estando sem cobertura vegetal no período pós-colheita da cana.

Parcelas experimentais, com preparo do solo e alinhamento no sentido da declividade do terreno, cuja média era $8,1 \%$, foram instaladas com as seguintes dimensões: a) em entressulcos - 0,50 m de largura e $0,75 \mathrm{~m}$ de comprimento $\left(0,38 \mathrm{~m}^{2}\right)$; b) em sulcos - 0,20 $\mathrm{m}$ de largura, $0,20 \mathrm{~m}$ de profundidade e 9,00 m de comprimento, pré-formados com uma enxada; c) erosão global - 3,50 m de largura e $11,00 \mathrm{~m}$ de comprimento $\left(38,5 \mathrm{~m}^{2}\right)$. As parcelas em entressulcos e macroparcelas foram delimitadas 
com chapas metálicas nas laterais e na parte superior. Todas as parcelas apresentavam calhas coletoras metálicas, em seus limites inferiores, convergentes para uma saída de 0,11 m de diâmetro.

O experimento foi conduzido num delineamento inteiramente casualizado (DIC), com três tratamentos (tipos de parcelas) e três repetições. As parcelas foram submetidas à chuva com intensidade de $80 \mathrm{~mm} \mathrm{~h}^{-1}$, durante 65 minutos, produzida por um simulador de chuvas de hastes rotativas do tipo Swanson, com bicos veejet 80100, previamente calibrado e nivelado no terreno, como proposto por SWANSON (1965). Medidas de vazões dos escoamentos superficiais e das concentrações de sedimentos foram realizadas no quinto minuto após o início da enxurrada e, a partir daí, a cada cinco minutos, conforme MARTINS FILHO (1999). Amostras de enxurrada foram coletadas em recipientes de vidro com capacidade de $1 \mathrm{~L}$, cronometrando-se o tempo de coleta. No laboratório, determinaram-se a concentração de sedimentos, o volume de solução e as taxas de perdas de solo, água e nutrientes no sedimento. A solução foi avaliada gravimetricamente, em balança com resolução de $0,01 \mathrm{~g}$, e, em seguida, as amostras foram deixadas em repouso por $24 \mathrm{~h}$ para a deposição de sedimentos. Após o período de repouso de $24 \mathrm{~h}$, as amostras foram levadas à estufa a $105{ }^{\circ} \mathrm{C}$ até secagem completa. Após a secagem, as amostras foram pesadas, determinando-se o peso de sedimento de cada uma.

A análise granulométrica do solo foi realizada pelo método da pipeta, utilizando uma solução de $\mathrm{NaOH} 0,1 \mathrm{~N}$ como dispersante químico e agitação com aparato de alta rotação (12.000 rpm) (GEE \& BAUDER, 1986). O LVef, na camada de 0,00 a $0,20 \mathrm{~m}$, apresentou teores médios de $653 \mathrm{~g} \mathrm{~kg}^{-1} \mathrm{de}$ argila, $169 \mathrm{~g} \mathrm{~kg}^{-1}$ de silte e $178 \mathrm{~g} \mathrm{~kg}^{-1}$ de areia. Nas análises químicas do solo e dos sedimentos erodidos, o cálcio, o magnésio, o potássio e o fósforo foram extraídos pelo método da resina trocadora de íons (RAIJ et al., 1987). O carbono orgânico foi determinado seguindo metodologia da EMBRAPA (1997). $\mathrm{O}$ pH foi determinado potenciometricamente em solução de $\mathrm{CaCl}_{2}$ 0,01 M. Atributos químicos do solo são apresentados na Tabela 1, os quais foram utilizados para estabelecer as taxas de enriquecimento do sedimento erodido por MO, P, K, Ca e Mg.

TABELA 1. Concentração média de matéria orgânica $(\mathrm{MO})$, fósforo $(\mathrm{P})$, potássio $(\mathrm{K})$, cálcio $(\mathrm{Ca})$ e magnésio (Mg) no solo original, na profundidade de 0,00 a 0,20 m (SOUZA, 2004).

\begin{tabular}{|c|c|c|c|c|}
\hline M.O. & $\mathrm{P}$ & $\mathrm{K}$ & $\mathrm{Ca}$ & $\mathrm{Mg}$ \\
\hline $\mathrm{g} \mathrm{dm}^{-3}$ & $\mathrm{mg} \mathrm{dm}^{-3}$ & --------- & $\mathrm{ol}_{\mathrm{c}} \mathrm{d}$ & ----------- \\
\hline 28 & 26 & 5 & 38 & 13 \\
\hline
\end{tabular}

Os dados obtidos foram submetidos ao Teste $\mathrm{F}$ da análise da variância de um delineamento inteiramente casualizado. Nas comparações múltiplas das médias, utilizou-se do teste de Tukey, a 5\% de probabilidade. Análises de correlações foram conduzidas entre os dados de perdas de solo, matéria orgânica e nutrientes obtidos por erosão em entressulcos, em sulcos e global. Para essas análises, foi utilizado o programa estatístico STATISTICA (STATSOFT, 1994). Os modelos ajustados foram utilizados em estimativas das perdas de solo, MO e nutrientes para fins de análise geoestatística da variabilidade espacial das mesmas. Nessa análise, utilizou-se de banco de dados de atributos físicos e químicos da camada superficial do solo $(0,00$ a $0,20 \mathrm{~m})$ estabelecido por SOUZA (2004). O solo foi amostrado numa posição de sopé, nos pontos de cruzamento de uma malha, com intervalos regulares de 50 m, num total de 206 pontos (40 ha) georreferenciados com GPS, Datum/elipsóide WGS-84.

As perdas de solo (A), erosão global, na área toda, ponto a ponto, foram determinadas com a equação universal de perdas de solo (EUPS), descrita por WISCHMEIER \& SMITH (1978) como:

$$
\mathrm{A}=\mathrm{R} \text { K LS C P }
$$

em que, 
A - perda de solo por unidade de área, $\mathrm{t} \mathrm{ha}^{-1}$;

$\mathrm{R}$ - erosividade da chuva, $\mathrm{MJ} \mathrm{mm} \mathrm{ha}^{-1} \mathrm{~h}^{-1}$;

$\mathrm{K}$ - erodibilidade do solo, $\mathrm{tha}^{-1} \mathrm{MJ}^{-1} \mathrm{~mm}^{-1}$ ha $\mathrm{h}$;

LS - fator para o efeito combinado do declive e do comprimento da rampa;

$\mathrm{C}$ - fator cobertura e manejo do solo, e

$\mathrm{P}$ - fator práticas conservacionistas.

A erosividade das chuvas (R) foi estimada em 7.291 $\mathrm{MJ} \mathrm{mm} \mathrm{ha}^{-1} \mathrm{~h}^{-1}$ ano $^{-1}$, por meio de método proposto por LOMBARDI NETO et al. (2000). O fator erodibilidade (K) foi estimado, ponto a ponto, utilizando a equação proposta por DENARDIN (1990):

$$
\mathrm{K}=0,00000748 \mathrm{M}+0,004448059 \mathrm{p}-0,06631175 \mathrm{DMP}+0,01039567 \text { X32 }
$$

em que,

M - novo silte (novo silte + nova areia);

p - permeabilidade codificada, segundo WISCHMEIER et al. (1971);

DMP - diâmetro médio ponderado das partículas do solo inferiores a 2,00 mm, e

X32 - nova areia $(\mathrm{MO} / 100)$.

$\mathrm{O}$ valor médio do fator $\mathrm{K}$ estimado foi de $0,015 \mathrm{t} \mathrm{ha}^{-1} \mathrm{MJ}^{-1} \mathrm{~mm}^{-1}$ ha $\mathrm{h}$, o qual não diferiu significativamente daquele determinado nas macroparcelas que foi de $0,010 \mathrm{t} \mathrm{ha}^{-1} \mathrm{MJ}^{-1} \mathrm{~mm}^{-1} \mathrm{ha} \mathrm{h}$. Na determinação do fator LS, seguiu-se o proposto por WISCHMEIER \& SMITH (1978). Já o fator C foi considerado igual a 0,06, conforme valor estabelecido por SERRA (2004), para cana-de-açúcar (planta). Para o fator P, adotaram-se valores propostos por WISCHMEIER \& SMITH (1978). A tolerância de perdas de solo por erosão $(\mathrm{T})$ foi determinada conforme o proposto por OLIVEIRA (2004).

A análise geoestatística de A, MO, P, K, Ca e Mg foi realizada seguindo-se metodologia descrita em VIEIRA et al. (1983) e ROBERTSON (1998), em três etapas: 1) análise espacial para obter o semivariograma; 2) escolha de modelo para ajustar o semivariograma, e 3) obtenção de valores das variáveis em estudo em local não amostrado, para interpolação por meio da krigagem. Para determinar a existência ou não da dependência espacial, ajustaram-se semivariogramas com o programa $\mathrm{GS}^{+}$ (ROBERTSON, 1998). Para dirimir dúvida na escolha do melhor modelo, para um mesmo semivariograma, adotaram-se como critérios o melhor coeficiente de determinação $\left(R^{2}\right)$ e a menor soma de quadrados do resíduo (SQR). Para a elaboração dos mapas de distribuição espacial das variáveis, foi utilizado o programa SURFER (1999).

\section{RESULTADOS E DISCUSSÃO}

As concentrações médias de $\mathrm{MO}, \mathrm{P}, \mathrm{K}, \mathrm{Ca}$ e $\mathrm{Mg}$ no sedimento foram influenciadas, significativamente, pelo método de determinação da erosão hídrica do solo (Tabela 2). As parcelas entressulcos apresentaram as maiores concentrações de $\mathrm{P}, \mathrm{K}$ e Ca, e as macroparcelas, as de $\mathrm{MO}$ e $\mathrm{Mg}$. Justificam-se os resultados nas parcelas entressulcos pela maior concentração de $\mathrm{P}$, $\mathrm{K}$ e $\mathrm{Ca}$ na superfície do solo. No geral, os sedimentos dos sulcos apresentaram as menores concentrações de P, K, $\mathrm{Ca}$ e $\mathrm{Mg}$ e os dos entressulcos, as menores de MO.

Segundo CASSOL et al. (2002), as perdas de nutrientes e MO aumentam com as de solo, enquanto as taxas de enriquecimento do sedimento erodido tendem a diminuir. Os resultados apresentados na Tabela 3 são concordantes com o descrito por CASSOL et al. (2002). 
TABELA 2. Concentrações médias de matéria orgânica (MO), fósforo $(\mathrm{P})$, potássio $(\mathrm{K})$, cálcio $(\mathrm{Ca})$ e magnésio ( $\mathrm{Mg}$ ) no sedimento erodido das parcelas em entressulcos, sulcos e macroparcelas.

\begin{tabular}{|c|c|c|c|c|c|}
\hline \multirow{2}{*}{ Parcelas } & MO & $\mathrm{P}$ & $\mathrm{K}$ & $\mathrm{Ca}$ & $\mathrm{Mg}$ \\
\hline & $\mathrm{g} \mathrm{dm}^{-3}$ & $\mathrm{mg} \mathrm{dm}^{-3}$ & -------------- & $\mathrm{mmol}_{\mathrm{c}} \mathrm{dm}^{-3}$ & --------------- \\
\hline Entressulcos & $37,6 \mathrm{c}$ & $110,0 \mathrm{a}$ & $6,3 \mathrm{a}$ & $51,1 \mathrm{a}$ & $13,7 \mathrm{~b}$ \\
\hline Sulcos & $43,0 \mathrm{~b}$ & $79,3 \mathrm{c}$ & $3,2 \mathrm{c}$ & $37,0 \mathrm{c}$ & $12,3 \mathrm{c}$ \\
\hline Macroparcelas & $45,4 \mathrm{a}$ & $99,3 \mathrm{~b}$ & $3,9 \mathrm{~b}$ & $48,8 \mathrm{~b}$ & $15,5 \mathrm{a}$ \\
\hline
\end{tabular}

Médias seguidas de mesma letra, na coluna, não diferem significativamente entre si, pelo teste de Tukey, a $5 \%$ de probabilidade.

TABELA 3. Taxas médias de enriquecimento do sedimento para MO, P, K, Ca e Mg.

\begin{tabular}{lccccc}
\hline Parcelas & MO & P & K & Ca & Mg \\
\hline Entressulcos & $1,34 \mathrm{c}$ & $4,30 \mathrm{a}$ & $1,17 \mathrm{a}$ & $1,33 \mathrm{a}$ & $1,10 \mathrm{~b}$ \\
Sulcos & $1,54 \mathrm{~b}$ & $3,09 \mathrm{c}$ & $0,59 \mathrm{c}$ & $0,96 \mathrm{c}$ & $0,98 \mathrm{c}$ \\
Macroparcela & $1,62 \mathrm{a}$ & $3,87 \mathrm{~b}$ & $0,73 \mathrm{~b}$ & $1,27 \mathrm{~b}$ & $1,24 \mathrm{a}$ \\
\hline
\end{tabular}

Médias seguidas de mesma letra, na coluna, não diferem significativamente entre si, pelo teste de Tukey, a 5\% de probabilidade.

Devido à limitada capacidade de transporte do fino fluxo superficial, durante o processo de erosão entressulcos, uma remoção seletiva das partículas finas do solo tende a ocorrer (NEARING et al., 2001). Já a desagregação nos sulcos é menos ou nenhum pouco seletiva, devido à alta erosividade e capacidade de transporte do fluxo concentrado de enxurrada (NEARING et al., 2001). No entanto, considerável enriquecimento pode ocorrer durante os processos de transporte e deposição. Essa última observação justifica-se pelos resultados obtidos nas macroparcelas, nas quais o fenômeno de erosão determinado foi o global. Nessas macroparcelas, as taxas de enriquecimento para $\mathrm{MO}, \mathrm{P}, \mathrm{K}, \mathrm{Ca}$ e $\mathrm{Mg}$ sempre foram superiores às dos sulcos. Partículas dispersas de argila e MO podem ser facilmente transportadas com a água (NEARING et al., 2001), o que é justificável pelos seus baixos valores de densidade. Desse modo, explicam-se as taxas de enriquecimento por MO apresentar a seguinte ordem: macroparcelas $>$ sulcos $>$ entressulcos (Tabela 3).

$\mathrm{Na}$ Tabela 4, pode-se observar que as maiores perdas de $\mathrm{MO}, \mathrm{P}, \mathrm{K}, \mathrm{Ca}$ e $\mathrm{Mg}$ ocorreram nos sulcos, os quais também apresentaram as maiores perdas de solo $\left(27,3 \mathrm{t} \mathrm{ha}^{-1}\right)$, comprovando que esse processo é pouco ou nada seletivo, conforme citou NEARING et al. (2001). As parcelas em entressulcos apresentaram as menores perdas de água $\left(37,6 \mathrm{~L} \mathrm{ha}^{-1}\right)$ e não houve diferença significativa entre as perdas de $\mathrm{MO}$ e $\mathrm{K}$ em relação àquelas obtidas nas macroparcelas.

TABELA 4. Perdas médias de solo, água, matéria orgânica e nutrientes.

\begin{tabular}{|c|c|c|c|c|c|c|c|}
\hline Parcelas & $\begin{array}{l}\text { Perda de } \\
\text { Solo }\end{array}$ & $\begin{array}{c}\text { Perda de } \\
\text { Água } \times 10^{-3}\end{array}$ & MO & $\mathrm{P}$ & $\mathrm{K}$ & $\mathrm{Ca}$ & $\mathrm{Mg}$ \\
\hline & $\mathrm{t} \mathrm{ha}^{-1}$ & $\mathrm{~L} \mathrm{ha}^{-1}$ & |------------ & --------- & $-\mathrm{kg} \mathrm{ha}^{-1}$ & ---------- & --------- \\
\hline Sulcos & $27,3 \mathrm{a}$ & $422,0 \mathrm{~b}$ & $889,51 \mathrm{a}$ & $2,23 \mathrm{a}$ & $3,73 \mathrm{a}$ & $21,25 \mathrm{a}$ & $4,10 \mathrm{a}$ \\
\hline Entressulcos & $0,7 \mathrm{~b}$ & $37,6 \mathrm{c}$ & $19,75 \mathrm{~b}$ & $0,08 \mathrm{c}$ & $0,18 \mathrm{bc}$ & $0,67 \mathrm{c}$ & $0,12 \mathrm{c}$ \\
\hline Macroparcela & $10,6 \mathrm{~b}$ & $774,7 \mathrm{a}$ & $337,29 \mathrm{~b}$ & $1,07 \mathrm{~b}$ & $1,59 \mathrm{~b}$ & $10,24 \mathrm{~b}$ & $1,91 \mathrm{~b}$ \\
\hline
\end{tabular}


As parcelas em entressulcos apresentaram, de modo significativo, as menores perdas de MO, P, $\mathrm{K}$, Ca e Mg, quando comparadas aos sulcos. Desse modo, as perdas de nutrientes, MO e solo, em função do tipo de erosão, tiveram a seguinte ordem: sulcos $>$ macroparcela $>$ entressulcos. Esses resultados são concordantes com os de CASTRO et al. (1986), os quais observaram que as perdas de matéria orgânica e nutrientes têm maior correlação com as perdas de solo que com as de água. Porém, os resultados da Tabela 4 são discordantes de CASSOL et al. (2002).

As perdas de $\mathrm{P}, \mathrm{K}$, Ca e Mg, nas macroparcelas, foram da ordem de $1,07 \mathrm{~kg} \mathrm{ha}^{-1} ; 1,59 \mathrm{~kg} \mathrm{ha}^{-1}$; $10,24 \mathrm{~kg} \mathrm{ha}^{-1}$, e 1,91 $\mathrm{kg} \mathrm{ha}^{-1}$, respectivamente. HERNANI et al. (1999) obtiveram, num LatossoloVermelho eutroférrico, no sistema convencional, em macroparcelas sem cobertura vegetal, valores de perdas de nutrientes por erosão da seguinte magnitude: $0,06 \mathrm{~kg} \mathrm{ha}^{-1}$ de P; 0,29 $\mathrm{kg} \mathrm{ha}^{-1} \mathrm{de} \mathrm{K}$; 2,2 $\mathrm{kg} \mathrm{ha}^{-1}$ de Ca, e $0,19 \mathrm{~kg} \mathrm{ha}^{-1}$ de $\mathrm{Mg}$.

Pelos resultados apresentados nas Tabelas 3 e 4, é possível afirmar, a exemplo de SCHICK et al. (2000), que a perda total de nutrientes e MO nos sedimentos erodidos é dependente da quantidade total de sedimentos transportados, além da concentração dos referidos nutrientes e MO nesses.

Regressões entre perdas de matéria orgânica, nutrientes e por erosão global foram estabelecidas e apresentaram coeficientes de determinação altamente significativos (Tabela 5).

TABELA 5. Modelos ajustados entre perdas de nutrientes ( $\left.\mathrm{Y}, \mathrm{kg} \mathrm{ha}^{-1}\right)$ e as perdas de solo $\left(\mathrm{A}, \mathrm{t} \mathrm{ha}^{-1}\right)$.

\begin{tabular}{cccc}
\hline Variável & $\mathrm{a}$ & $\mathrm{b}$ & $\mathrm{R}^{2}$ \\
\hline $\mathrm{MO}^{1}$ & 29,467 & 1,031 & $1,00^{* *}$ \\
$\mathrm{P} \dagger$ & 0,114 & 0,079 & $0,99 *$ \\
$\mathrm{~K} \dagger$ & 0,124 & 0,133 & $0,99^{*}$ \\
$\mathrm{Ca}^{1}$ & 1,299 & 0,852 & $1,00^{* *}$ \\
$\mathrm{Mg}^{1}$ & 0,233 & 0,873 & $1,00^{* *}$ \\
\hline
\end{tabular}

Modelo: ${ }^{1} \ln \mathrm{Y}=\mathrm{a} \ln (\mathrm{A}){ }^{\mathrm{b}} ;{ }^{\dagger} \ln \mathrm{Y}=\mathrm{a}+\mathrm{b} \ln (\mathrm{A}) ; \mathrm{a}$ e $\mathrm{b}=$ coeficientes; $\mathrm{R}^{2}=$ coeficiente de determinação; $*$ e ** significativo a $5 \%$ e $1 \%$, pelo teste $\mathrm{F}$, respectivamente.

As estatísticas descritivas das variáveis A, MO, P, K, Ca e Mg são apresentadas na Tabela 6.

TABELA 6 . Estatísticas descritivas para as perdas de solo (A), matéria orgânica (MO) e nutrientes (P, $\mathrm{K}, \mathrm{Ca}$ e $\mathrm{Mg}){ }^{1}$

\begin{tabular}{lcrrrrrr}
\hline Parâmetros & Número & Média & Mediana & C.V. & Assimetria & Kurtosis & $\mathrm{d}^{3}$ \\
\hline A & 206 & 4,42 & 2,26 & 143,4 & 2,64 & 6,77 & 0,26 \\
MO & 206 & 139,28 & 68,37 & 148,4 & 2,70 & 7,04 & 0,26 \\
P & 206 & 0,46 & 0,29 & 108,0 & 2,65 & 6,78 & 0,26 \\
K & 206 & 0,71 & 0,43 & 118,3 & 2,65 & 6,78 & 0,26 \\
CA & 206 & 4,23 & 2,61 & 119,6 & 2,36 & 5,41 & 0,23 \\
MG & 206 & 0,79 & 0,47 & 122,9 & 2,41 & 5,61 & 0,23 \\
$\ln (\mathrm{A})$ & 206 & 0,76 & 0,82 & 157,2 & 0,27 & $-0,66$ & $0,06^{\mathrm{ns}}$ \\
$\ln (\mathrm{O})$ & 206 & 4,17 & 4,22 & 29,6 & 0,27 & $-0,66$ & $0,06^{\mathrm{ns}}$ \\
$\ln (\mathrm{P})$ & 206 & $-1,11$ & $-1,24$ & 67,0 & 0,99 & 0,41 & 0,12 \\
$\ln (\mathrm{K})$ & 206 & $-0,76$ & $-0,86$ & 110,7 & 0,83 & 0,06 & 0,11 \\
$\ln (\mathrm{Ca})$ & 206 & 0,91 & 0,96 & 112,0 & 0,27 & $-0,66$ & $0,06^{\mathrm{ns}}$ \\
$\ln (\mathrm{Mg})$ & 206 & $-0,79$ & $-0,76$ & 131,8 & 0,27 & $-0,66$ & $0,06^{\mathrm{ns}}$ \\
\hline
\end{tabular}

${ }^{1} \mathrm{~A}$ em t ha ${ }^{-1}$ e MO, P, K, Ca e Mg em kg ha ${ }^{-1} ;{ }^{2}$ Coeficiente de variação $(\%) ;{ }^{3} \mathrm{~d}=$ estatística do teste de KolmogorovSmirnov; ${ }^{\text {ns }}=$ não-significativo a $5 \%$ de probabilidade. 
Resultados referentes ao teste de Kolmogorov-Smirnov indicaram a não-normalidade dos dados de A, MO, P, K, Ca e Mg . Porém, quando os seus valores foram testados quanto à distribuição lognatural (ln), apenas as perdas de $\mathrm{P}$ e $\mathrm{K}$ não se ajustaram a tal distribuição. Contudo, os valores da média e mediana, para cada uma das variáveis transformadas, são próximos, demonstrando haver distribuições simétricas. Segundo ISAAKS \& SRIVASTAVA (1989), mais importante que a normalidade dos dados é a ocorrência do efeito proporcional em que a média e a variância dos dados não sejam constantes na área de estudo. Esse fato não ocorreu, visto que os semivariogramas apresentaram patamares bem definidos. WARRICK \& NIELSEN (1980) afirmaram que atributos mecânicos do solo apresentam distribuição normal, enquanto atributos hidráulicos têm distribuição não-normal. Considerando-se critérios propostos por WARRICK \& NIELSEN (1980) para o coeficiente de variação (C.V.), observa-se, na Tabela 6, que todas as variáveis apresentaram C.V. alto $(29,6$ a $157,2 \%)$. Embora o emprego do C.V. permita comparar a variabilidade entre amostras, com unidades diferentes, o seu emprego não deve ser generalizado (SOUZA, 2004). Desse modo, a dependência espacial dos atributos pode ser melhor avaliada com técnicas geoestatísticas.

A partir das regressões apresentadas na Tabela 5, foram estimados semivariogramas, após a transformação dos dados de perdas de solo (A), MO e nutrientes, utilizando a função logaritmo natural. Os resultados da análise geoestatística são apresentados na Figura 1. Todas as variáveis, após transformadas, apresentaram dependência espacial. A semivariância estimada das variáveis transformadas ajustou-se ao modelo esférico. Segundo TRANGMAR et al. (1987), o modelo esférico é considerado o mais apto para descrever o comportamento de atributos do solo. Quanto à relação entre o efeito pepita e o patamar dos semivariogramas $\left(\mathrm{GD}=\mathrm{C}_{0} /\left(\mathrm{C}_{0}+\mathrm{C}_{1}\right)\right.$ ), segundo critérios de CAMBARDELLA et al. (1994), é possível afirmar que os valores transformados das perdas de solo $(\mathrm{GD}=13 \%), \quad \mathrm{MO}(\mathrm{GD}=13 \%), \mathrm{P}(\mathrm{GD}=13 \%), \mathrm{K}(\mathrm{GD}=14 \%)$ e $\mathrm{Ca}(\mathrm{GD}=13 \%)$ apresentaram forte dependência espacial. Já as perdas de $\mathrm{Mg}$ apresentaram moderado grau de dependência espacial $(\mathrm{GD}=32 \%)$.

Em termos do alcance (a), verifica-se que esse variou na faixa de 1.007 a $1.013 \mathrm{~m}$. Cumpre ressaltar que o alcance representa a distância máxima em que os pontos amostrais estão correlacionados entre si.

Os parâmetros dos semivariogramas propiciaram estimar valores de A, MO e nutrientes em locais não amostrados por krigagem (Figura 2). Pode-se observar que as perdas de solo, MO, P, K Ca e $\mathrm{Mg}$ apresentaram valores na faixa de 0 a $24 \mathrm{t} \mathrm{ha}^{-1}$; 0 a $800 \mathrm{~kg} \mathrm{ha}^{-1} ; 0,1$ a 3,3 $\mathrm{kg} \mathrm{ha}^{-1} ; 1,2$ a 4,8 $\mathrm{kg} \mathrm{ha}^{-1}$; 0 a 24,0 $\mathrm{kg} \mathrm{ha}^{-1}$, e 0 a 3,8 $\mathrm{kg} \mathrm{ha}^{-1}$, respectivamente. Os valores de perdas de solo, considerados como toleráveis (T) para o LVef, foram estimados, conforme OLIVEIRA (2004), em 12,1 t ha ${ }^{-1}$ ano $^{-1}$. Tal estimativa é semelhante à determinada por LOMBARDI \& BERTONI (1975). Na Figura 2a, verificase que há poucos locais com perdas iguais ou superiores a T, permitindo inferir que há condições de sustentabilidade do solo quanto à conservação das suas propriedades físicas e químicas na quase totalidade da área estudada. Os padrões de distribuição das perdas de nutrientes são muito semelhantes, visto serem funções diretas da erosão global. 
a

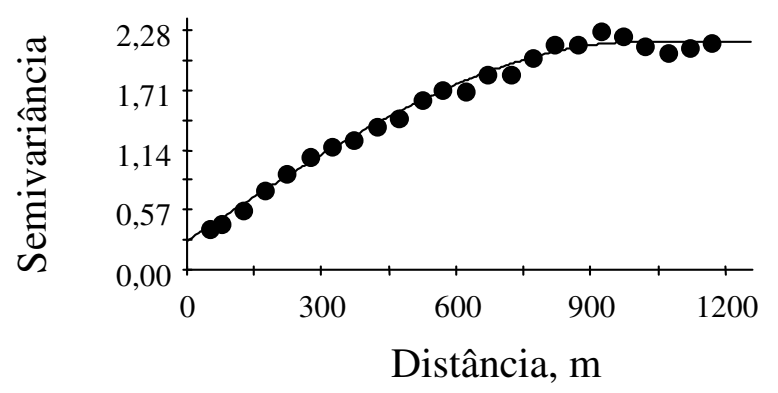

Esf. ( 0,$275 ; 1,899 ; 1011 ; 0,99)$

c

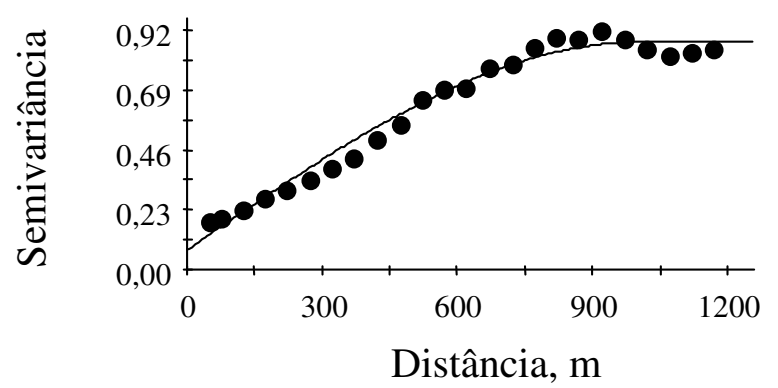

Esf. ( 0,074; 0,798; 1007; 0,98)

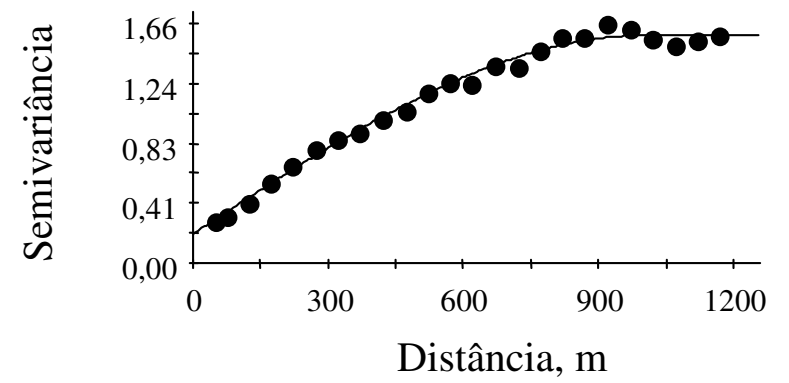

Esf. ( 0,$198 ; 1,381 ; 1009 ; 0,99)$

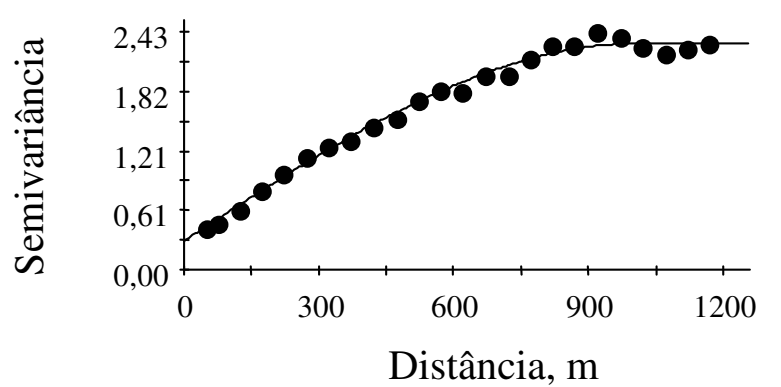

Esf. ( 0,$291 ; 2,020 ; 1010 ; 0,99)$

d

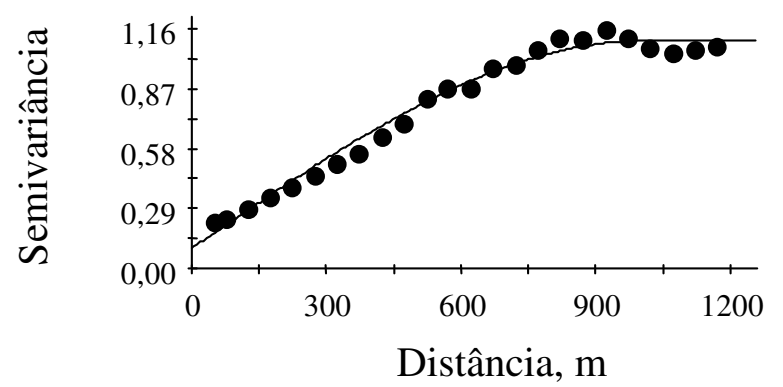

Esf. ( 0,096; 1,008; 1013;0,98 )

e

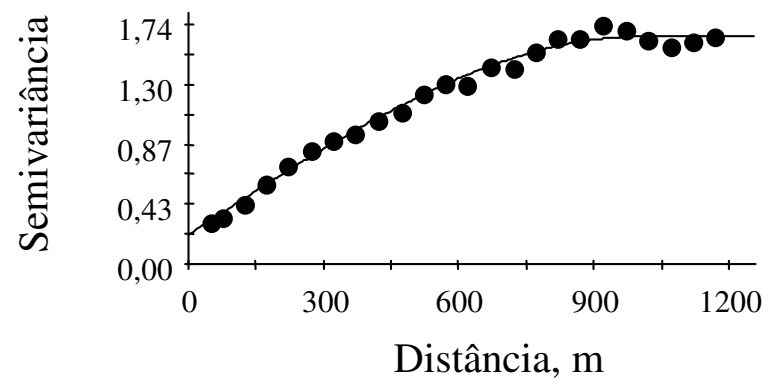

Esf. $(0,209 ; 0,446 ; 1008 ; 0,99)$

FIGURA 1. Semivariogramas estimados: a) perdas de solo (A); b) MO; c) P; d) $\mathrm{K}$; e) Ca e f) $\mathrm{Mg}$. Esf. $\left(\mathrm{C}_{\mathrm{o}} ; \mathrm{C}_{1} ; \mathrm{a} ; \mathrm{r}^{2}\right)=$ modelo esférico, $\mathrm{C}_{\mathrm{o}}=$ efeito pepita, $\mathrm{C}_{1}=$ patamar, $\mathrm{a}=$ alcance $\mathrm{e}$ $\mathrm{r}^{2}=$ coeficiente de determinação. 

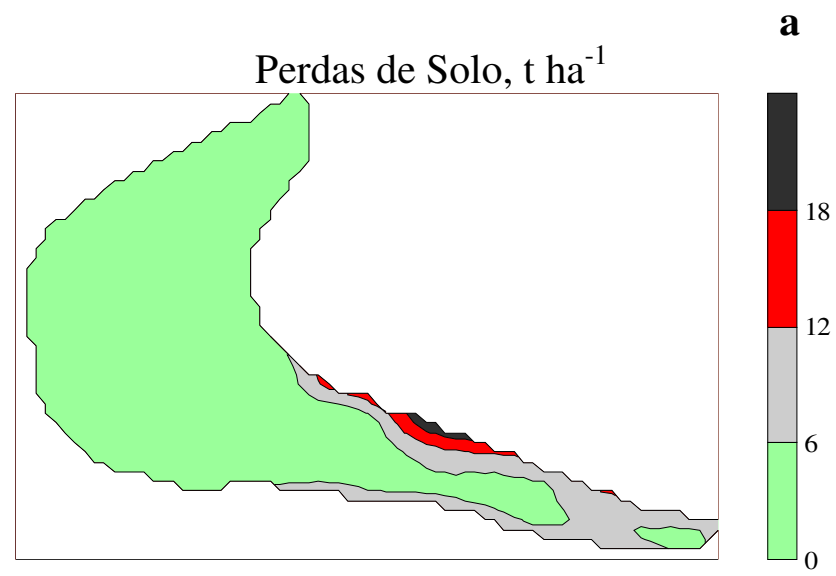

c

Perdas de Fósforo, $\mathrm{kg} \mathrm{ha}^{-1}$

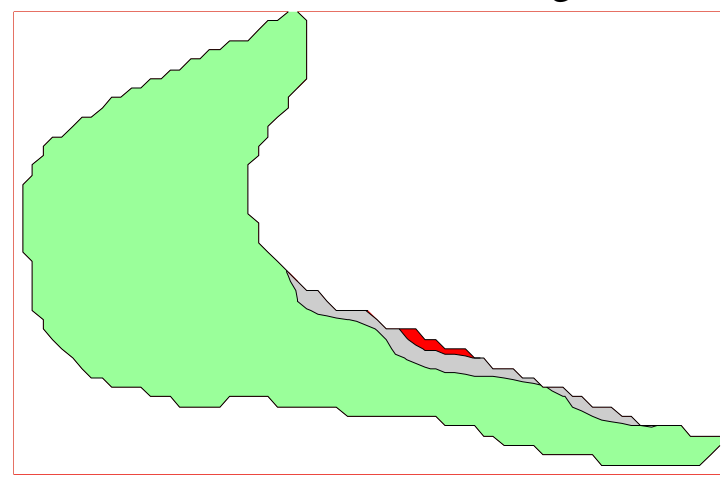

Perdas de Cálcio, $\mathrm{kg} \mathrm{ha}^{-1}$

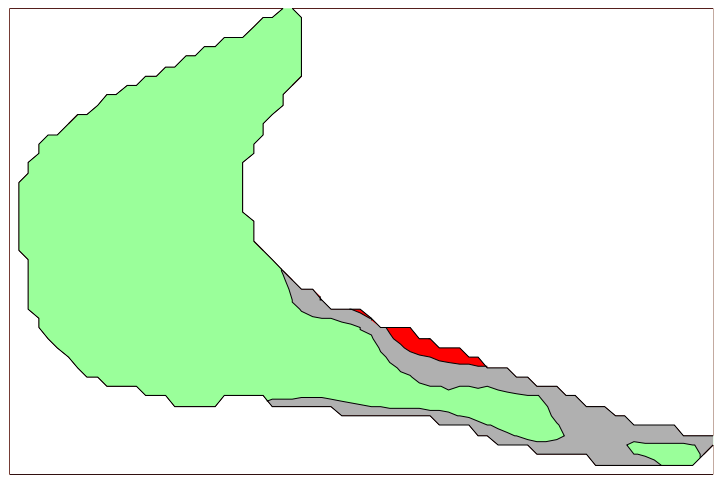

e

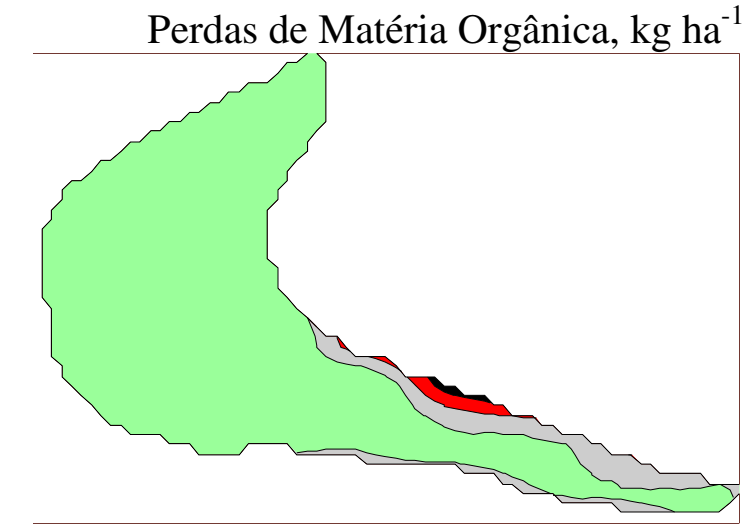

Perdas de Potássio, $\mathrm{kg} \mathrm{ha}^{-1}$
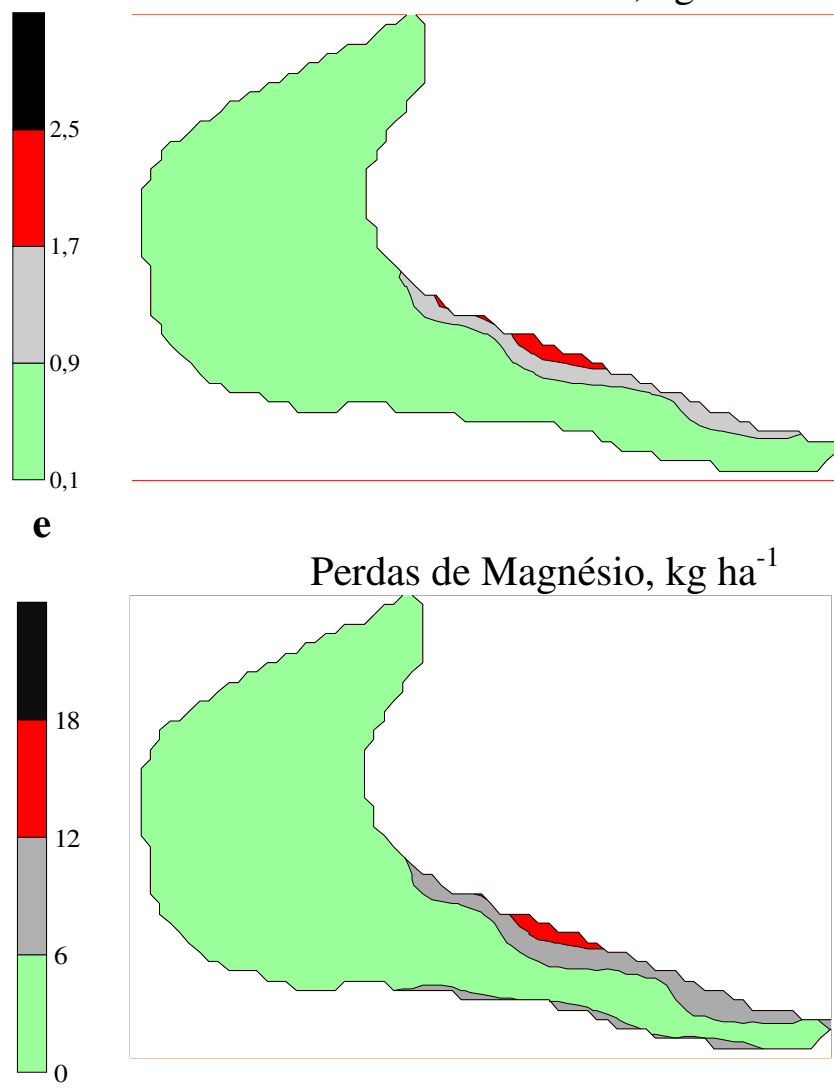

Perdas de Magnésio, $\mathrm{kg} \mathrm{ha}^{-1}$

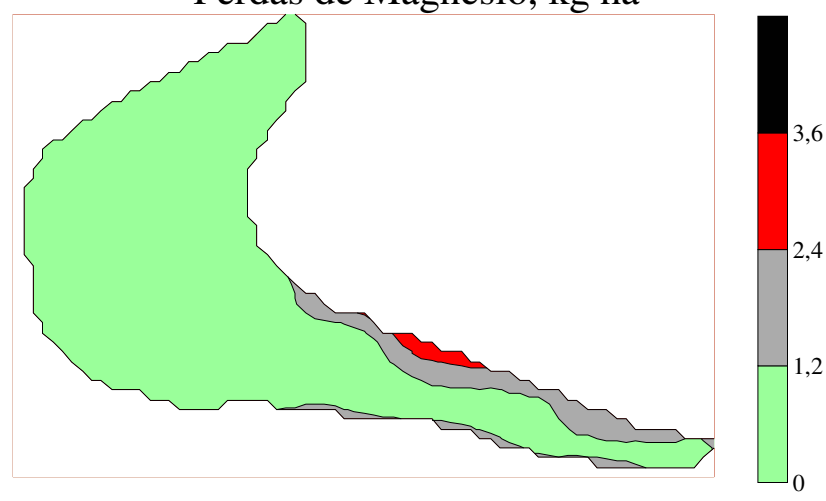

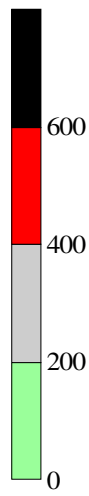

d

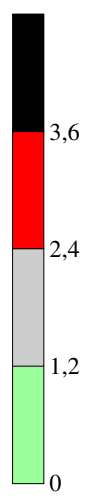

f

FIGURA 2. Distribuição espacial das perdas médias anuais de solo (A), matéria orgânica e nutrientes.

\section{CONCLUSÕES}

As perdas de nutrientes e solo, em função do tipo de erosão, obedecem à seguinte ordem: sulcos $>$ entressulcos $>$ global.

As perdas de solo (A), MO, P, K e Ca têm forte grau de dependência espacial, enquanto as perdas de Mg têm moderado grau de dependência espacial.

Mapas da distribuição das referidas perdas demonstram, em termos médios anuais, que há sustentabilidade do solo, quanto à conservação das propriedades físicas e químicas na quase totalidade da área estudada. 


\section{REFERÊNCIAS}

CAMBARDELLA, C.A.; MOORMAN, T.B.; NOVACK, J.M.; PARKIN, T.B.; KARLEN, D.L.; TURCO, R.F.; KNOPKA, A.E. Field-scale variability of soil properties in central Iowa Soils. Soil Science Society American Journal, Madison, v.58, n.5, p.1501-11, 1994.

CASSOL, E.A.; LEVIEN, R.; ANGHINONI, I.; BADELUCCI, M.P. Perdas de nutrientes por erosão em diferentes métodos de melhoramento de pastagem nativa no Rio Grande do Sul. Revista Brasileira de Ciência do Solo, Viçosa, v.26, n.3, p.705-12, 2002.

CASTRO, O.M.; LOMBARDI NETO, F.; QUAGGIO, J.A.; MARIA, I.C.; VIEIRA,S.R.; DECHEN, S.C.F. Perdas por erosão de nutrientes vegetais na sucessão soja/trigo em diferentes sistemas de manejo. Revista Brasileira de Ciência do Solo, Campinas, v.10, n.3, p.293-7, 1986.

DENARDIN, J.E. Erodibilidade do solo estimada por meio de parâmetros físicos e químicos.1990. 113 f. Tese (Doutorado em Solos e Nutrição de Plantas) - Escola Superior de Agricultura "Luiz de Queiroz”, Universidade de São Paulo, Piracicaba, 1990.

EMPRESA BRASILEIRA DE PESQUISA AGROPECUÁRIA. Manual de métodos de análise de solo. 2.ed. Rio de Janeiro, 1997. 212 p.

EMPRESA BRASILEIRA DE PESQUISA AGROPECUÁRIA. Centro Nacional de Pesquisa de Solos. Sistema brasileiro de classificação de solos. Rio de Janeiro, 1999. 412 p.

FOSTER, G.R Modeling the erosion process. In: HAAN,C.T.; JOHNSON, H.P.; BRAKENSIEK, D.L. Hydrologic modeling of small watersherds. St. Joseph: American Society of Agricultural Engineers, 1982. p.296-380. (Monograph, 5).

GEE, G.W.; BAUDER, J.W. Particle-size analysis. In: KLUTE, A. Methods of soil analysis. Part 1. $2^{\text {nd }}$ ed. Madison: ASA, 1986. p.383-411. (Agronomy Monography, 9).

HERNANI, L.C.; KURIHARA, C.H.; SILVA W.M. Sistema de manejo de solos e perdas de nutrientes e matéria orgânica por erosão. Revista Brasileira de Ciência do Solo, Viçosa, v.23, n.1, p.145-54, 1999.

ISAAKS, E.H.; SRIVASTAVA, R.M. An introduction to applied geoestatistics. New York: Oxford, University Press, 1989. 561 p.

LAL, R.; ELLIOT, W. Erodibility and erosivity. In: LAL, R. Soil erosion research methods. Ankeny: Soil and Water Conservation Society/Saint Lucie Press, 1994. p.11-332.

LOMBARDI NETO, F.; BERTONI, J. Tolerância de perdas de terra para solos do Estado de São Paulo. Campinas, 1975. 12 p. (Boletim Técnico, 28)

LOMBARDI NETO, F.; PRUSKI, F.F.; TEIXEIRA, A. de F. Sistema para cálculo da erosividade da chuva para o Estado de São Paulo. Viçosa: Sociedade Brasileira de Ciência do Solo, 2000. 1 CDROM.

MARTINS FILHO, M.V. Modelagem do processo de erosão entressulcos em latossolos de Jaboticabal - SP. 1999. 140 f.Tese (Doutorado em Solos e Nutrição de Plantas) - Universidade Federal de Lavras, Lavras, 1999.

NEARING, M.A.; NORTON, D.L.; ZHANG, X. Soil erosion and sedimentation. In: RITTER, W.F.; SHIRMOHAMMADI, A. (Eds.). Agricultural nopoint source pollution. Boca Raton: Lewis Publishers, 2001. p.29-58. 
OLIVEIRA, F.P. de. Determinação da tolerância de perdas por erosão para as principais Ordens de solos do Estado da Paraíba. 2004. 92 f. Monografia (Trabalho de Graduação em Engenharia Agronômica) - Centro de Ciências Agrárias, Universidade Federal da Paraíba, Areia, 2004.

RAIJ, B. van; QUAGGIO, J.A.; CANTARELLA, H.; FERREIRA, M.E.; LOPES, A.S.; BATAGLIA, O.C. Análise química do solo para fins de fertilidade. Campinas: Fundação Cargill, 1987. 170 p.

ROBERTSON, G.P. GS ${ }^{+}$: Geostatistics for the environmental sciences - GS ${ }^{+}$User's Guide. Plainwell: Gamma Design Software, 1998. 152 p.

SERRA, E.A. Expectativa e risco de erosão dos solos da FCAV/UNESP - Jaboticabal (SP). 2004. 75 f. Monografia (Trabalho de Graduação em Zootecnia) - Faculdade de Ciências Agrárias e Veterinárias, Universidade Estadual Paulista, Jaboticabal, 2004.

SCHICK, J.; BERTOL, I.; BATISTELA, O.; BALBINOT JÚNIOR, A.A. Erosão hídrica em cambissolo húmico alumínico submetido a diferentes sistemas de preparo e cultivo do solo. II - Perdas de nutrientes e carbono orgânico. Revista Brasileira de Ciência do Solo, Viçosa, v.24, n.2, p.437-47, 2000.

SOUZA, Z.M. Variabilidade espacial e atributos de um latossolo sob diferentes formas do relevo. 2004. 141 f. Tese (Doutorado em Produção Vegetal) - Faculdade de Ciências Agrárias e Veterinárias, Universidade Estadual Paulista, Jaboticabal, 2004.

STATSOFT. Statistica: quick reference. Tulsa: StatSoft, 1994. 148 p.

SURFER. Surfer 7.0. contouring and 3D surface mapping for scientist's engineers. User's Guide. New York: Golden Software, 1999. 619 p.

SWANSON, N.P. Rotating-boom rainfall simulator. Transactions of the ASAE, St. Joseph, v.8, n.1, p.71$2,1965$.

TRANGMAR, B.B.; YOST, R.S.; WADE, M.K.; UEHARA, G.; SUDJADI, M. Spatial variation of soil properties and rice yield on recently cleared land. Soil Science Society American Journal, Madison, v.51, p.668-74, 1987.

VIEIRA, S.R.; HATFIELD, J.L.; NIELSEN, D.R.; BIGGAR, J.W. Geoestatiscal theory and application to variability of some agronomical properties. Hilgardia, Oakland, v.51, n.1, p.1-75, 1983.

WALTON, R.S.; VOLKER, R.E.; BRISTOW, K.L.; SMETTEM, K.R.J. Experimental examination of solute transport by surface runoff from low-angle slopes. Journal of Hydrology, Amsterdam, v.233, n.1-4, p.19-36, 2000.

WARRICK, A.W.; NIELSEN, D.R. Spatial variability of soil physical properties in the field. In: HILLEL, D. (Ed.). Applications of soil physics. New York: Academic Press, 1980. cap. 2, p.319-44.

WISCHMEIER, W.H.; JOHNSON, C.B.; CROSS, B.V. A soil erodibility nomograph for farmland and construction sites. Journal of Soil and Water Conservation, Ankeny, v.26, n.5, p.183-9, 1971.

WISCHMEIER, W.H.; SMITH, D.D. Predicting rainfall erosion losses: a guide to conservation planning. Washington: U.S. Department of Agriculture, 1978. 58 p. (Handbook, 537). 